\title{
The influence of dynamic environmental interactions on detection efficiency of acoustic transmitters in a large, deep, freshwater lake
}

\author{
Natalie V. Klinard ${ }^{1 *} \mathbb{D}$, Edmund A. Halfyard², Jordan K. Matley ${ }^{1}$, Aaron T. Fisk ${ }^{1}$ and Timothy B. Johnson ${ }^{3}$
}

\begin{abstract}
Background: Acoustic telemetry is an increasingly common method used to address ecological questions about the movement, behaviour, and survival of freshwater and marine organisms. The variable performance of acoustic telemetry equipment and ability of receivers to detect signals from transmitters have been well studied in marine and coral reef environments to inform study design and improve data interpretation. Despite the growing use of acoustic telemetry in large, deep, freshwater systems, detection efficiency and range, particularly in relation to environmental variation, are poorly understood. We used an array of $9069-\mathrm{kHz}$ acoustic receivers and 8 sentinel range transmitters of varying power output deployed at different depths and locations approximately 100-9500 m apart for 215 days to evaluate how the detection efficiency of acoustic receivers varied spatially and temporally in relation to environmental conditions.

Results: The maximum distance that tags were detected ranged from 5.9 to $9.3 \mathrm{~km}$. Shallow tags consistently had lower detection efficiency than deep tags of the same power output and detection efficiency declined through the winter months (December-February) of the study. In addition to the distance between tag and receiver, thermocline strength, surface water velocity, ice thickness, water temperature, depth range between tag and receiver, and number of fish detections contributed to explaining variation in detection efficiency throughout the study period. Furthermore, the most significant models incorporated interactions between several environmental variables and tag-receiver distance, demonstrating the complex temporal and spatial relationships that exist in heterogeneous environments.

Conclusions: Relying on individual environmental variables in isolation to interpret receiver performance, and thus animal behaviour, may be erroneous when detection efficiency varies across distances, depths, or tag types. As acoustic telemetry becomes more widely used to study ecology and inform management, it is crucial to understand its limitations in heterogeneous environments, such as freshwater lakes, to improve the quality and interpretation of data. We recommend that in situ range testing and retrospective analysis of detection efficiency be incorporated into study design for telemetry projects. Furthermore, we caution against oversimplifying the dynamic relationship between detection efficiency and environmental conditions for the sake of producing a correction that can be applied directly to detection data of tagged animals when the intended correction may not be justified.
\end{abstract}

Keywords: Acoustic telemetry, Detection efficiency, Detection range, Great Lakes, Passive monitoring, Range testing

\footnotetext{
*Correspondence: natalie.klinard@gmail.com

${ }^{1}$ Great Lakes Institute for Environmental Research, University of Windsor,

Windsor, ON, Canada

Full list of author information is available at the end of the article
} 


\section{Background}

Acoustic telemetry is a valuable tool that is used to investigate the movement and behaviour of aquatic organisms. The ability to passively track the movement of tagged individuals on fine spatial and temporal scales has played an important role in the research of aquatic ecosystems and informing fisheries management and conservation strategies [1-3]. Recent advances in acoustic telemetry $[4,5]$, such as the miniaturization of transmitters and increased tag life, have enabled scientists to address questions about the fundamental ecology of aquatic organisms that were previously unattainable including their distributions, survival, spawning, habitat use, and trophic interactions $[1,6,7]$.

Passive acoustic telemetry requires an acoustic transmitter (hereafter tag) that emits ultrasonic sounds (pings) at certain intervals to be detected, decoded, and recorded by a submerged acoustic hydrophone and receiver (hereafter receiver) at a fixed location [8]. When the receiver successfully detects and decodes a transmitted sequence of pings (hereafter detection), the time, tag ID, and any additional sensor measurements, such as pressure (depth) or temperature, associated with the detection are recorded.

Detection efficiency (DE) is defined as the probability of successfully detecting a single transmission of a tag, whereas detection range (DR) refers to the distance from a receiver that a transmission is estimated to be detected given a specific DE [9]. DE depends primarily on the distance between the tag and receiver at the time of signal transmission due to the geometric spreading of the wavefront through water, but there is a suite of biotic and abiotic factors that also influence the rate of energy attenuation and absorption of sound as the signal travels through water $[9,10]$. It is important to comprehend the relationship between DE and different factors in a telemetry study to understand the quality of information obtained, enable more accurate interpretation of telemetry data, and ultimately, to make stronger inferences about the ecology of the study organisms. For example, Payne et al. [11] demonstrated that variation in DE of tagged cuttlefish (Sepia apama) created the appearance of diel activity patterns that were not necessarily present.

Some variables that influence the strength of a signal as it approaches a receiver may be controlled through study design $[12,13]$, such as acoustic tag power output, transmission interval, receiver orientation, and receiver depth. However, there are many other factors associated with environmental conditions or animal behaviour that are difficult to control for [14]. Factors affecting DE may remain relatively constant throughout the duration of a study, such as the refraction and reflection of signals caused by bathymetry and submerged structures, or the dissolved particle concentration of marine versus freshwater environments. Factors that may be more likely to change temporally include turbidity, air entrainment, algal blooms, ice cover, wind, water flow, waves, precipitation, water temperature, and water column stratification $[15,16]$. In addition, environmental noise can be caused by external human influence (e.g., boat motors; [8]) or biological components of the environment (e.g., shrimp; [8]) and may interfere with receipt of the transmission pings that make up a detection [17]. Furthermore, a high density of tags within the DR of a receiver can result in transmissions from multiple acoustic tags arriving at the receiver at approximately the same time and causing a collision of signals, preventing one or more tags from being decoded or creating a false detection sequence [18].

DE and DR within a receiver array are unique for each study and should be evaluated prior to the start of an acoustic telemetry project to help inform study design. The most common technique employed to quantify DE is static range testing, which uses acoustic tags deployed at fixed distances (i.e., sentinel tags) from a receiver [10]. Static range testing is often performed for long durations (e.g., weeks, months) to capture temporal scales relevant to the study objectives and evaluate the impacts of varying environmental conditions [19]. Mobile range testing is used less frequently and is performed by towing an acoustic tag near one or more receivers to evaluate DE and DR at a specific time and environmental condition [20]. Mobile range testing is less comprehensive and may be misleading depending on the environmental conditions, boat motor noise, time of day, and depth of tag [19]. Nevertheless, the most effective method of range testing varies by study and ultimately depends on the objectives, environment, and characteristics of the study animals.

As acoustic telemetry has become an increasingly popular method to track aquatic animals in the past three decades, studies evaluating DE and DR have similarly become more prevalent to accompany this growth [19]. DR has been examined across vast spatial scales in a variety of environments [19] revealing that the effect an environmental variable has on DE can often be unique to that location [20,21]. Furthermore, certain types of environments (e.g., river, lake, sea) often experience a specific range of variation of environmental variables (e.g., rivers often exhibit higher flow rates than lakes). How and de Lestang [22] and Cagua et al. [23] found that water temperature had a significant negative relationship with DE on reefs in south-western Australia and Saudi Arabia, respectively, while Simpfendorfer et al. [14] and Heupel et al. [24] found no significant effect of water temperature on DE in a Florida river and lagoon. Similarly, different 
studies reported a significant positive relationship [23], significant negative relationship [25], and no significant relationship [26, 27] between DE and wind speed. While several studies have evaluated the impact of individual environmental variables on DE [20,28], few studies have considered the interactions between them and how these relationships may change spatially [23]. Since DE is ultimately a function of distance and a combination of environmental variables, it is valuable to understand not only the temporal variability in DE caused by environmental conditions, but also how spatial variation impacts this relationship as well.

The majority of range test studies occur in marine environments with a focus on reef ecosystems despite the increasing prevalence of acoustic telemetry in freshwater systems. The Laurentian Great Lakes is the world's largest freshwater system and hosts numerous acoustic telemetry projects under the Great Lakes Acoustic Telemetry Observation System (GLATOS, https://glatos.glos. us) with over 76 projects, 44 species and 11,500 tagged fishes and more than 285 million detections as of February 2019. However, there are few DE and DR studies in the Great Lakes to support the vast assortment of telemetry projects [10]. Further, acoustic telemetry studies in temperate or northern freshwater lakes also encounter seasonal thermal stratification and winter ice cover. The effect of these abiotic conditions on acoustic gear performance is poorly understood.

In this study, we aimed to address knowledge gaps in acoustic telemetry literature by utilizing an extensive telemetry dataset from a large, deep, freshwater lake to answer questions about the relationship between DE and the environment through time and space. We examined spatial and temporal variability in the DE and DR of three acoustic tag types over a 7-month period (Oct. 2015-May 2016) in Lake Ontario, the 10th largest lake by volume in the world. We chose to analyze DE and DR in Lake Ontario because of its wide range of depths, variable habitats, seasonal fluctuations (e.g., thermal stratification, ice cover), and the availability of an extensive telemetry receiver array. Our specific objectives were: (1) to determine DR in Lake Ontario for three types of acoustic tags, (2) to examine spatial and temporal variability in DE across tags of different power output, and (3) to assess the relationship between DE and environmental variables and evaluate the relative impact of interactions between distance and environmental variables on $\mathrm{DE}$.

\section{Methods}

\section{Study site}

The telemetry study was performed in the St. Lawrence Channel of eastern Lake Ontario $\left(43^{\circ} 55.517^{\prime} \mathrm{N}, 76^{\circ}\right.$ 31.354' W) from August 2015 to May 2016 (Fig. 1). The
St. Lawrence Channel is a deep underwater valley located near the Canada-USA border that extends $24 \mathrm{~km}$ to form a major connection between Lake Ontario and the St. Lawrence River. This bathymetric feature is approximately $4 \mathrm{~km}$ wide, reaching depths of $50-60 \mathrm{~m}$ in the center of the valley and bordered by shallow water reefs less than 20-m deep on either side. In August 2015, five acoustic receivers (69-kHz VR2W; Vemco Ltd., Bedford, NS, Canada) were deployed at a depth of approximately $55 \mathrm{~m}$ (instrument depth $\sim 52 \mathrm{~m}$ ) and spaced 100-150 m apart to create a range of different distances between the tags and receivers at which to measure DE (Figs. 1, 2). A total of 8 acoustic tags (Vemco Ltd., Bedford, NS, Canada) were also deployed in four groups at different distances and two depths (shallow and deep) in the center of the study site (Fig. 2; Table 1). These included three V9-2x 69-kHz range tags (power output $145 \mathrm{~dB}$, nominal delay $1800 \mathrm{~s}$, random interval 1750-1850 s), one V13-1X $69-\mathrm{kHz}$ range tag (power output $153 \mathrm{~dB}$, nominal delay $1800 \mathrm{~s}$ ), and four V16-6X 69-kHz range tags (power output $158 \mathrm{~dB}$, nominal delay $1800 \mathrm{~s}$ ) to test $\mathrm{DE}$ and $\mathrm{DR}$ for tags of varying power and battery life. All tags had an estimated battery life of $>400$ days. The tag types in this study were selected based on several ongoing acoustic telemetry studies in Lake Ontario that utilize each of the three tag types. The first group of tags (one V9, one V16) and the second group of tags (one V16) were deployed on tag moorings that consisted of a cinder block $(\sim 16 \mathrm{~kg})$ anchor connected to a $28-\mathrm{cm}$ trawl float by a 3-m length of 1.1-mm polypropylene rope (Fig. 2). Both groups of tags were deployed at depth and attached $\sim 2 \mathrm{~m}$ from bottom. The third and fourth groups of tags were deployed attached to a receiver mooring that featured a length of rope with a buoy extending to $10 \mathrm{~m}$ below the surface that was outfitted with HOBO Pendant loggers (Onset, Cape Cod, MA, USA) to track changes in water temperature at various depths in the water column. The deep group of tags (one V9, one V13, oneV16) was situated below the thermocline at a depth of $50 \mathrm{~m}$, while the shallow group (one V9, one V16) was above the thermocline at a depth of $11 \mathrm{~m}$ to evaluate the impact of tag depth and thermal stratification on DE (Fig. 2).

An array of 85 acoustic receivers $(69-\mathrm{kHz}$ VR2W) was deployed in October 2015 as part of a project to track the movements of tagged bloater (Coregonus hoyi) in Lake Ontario (Fig. 1). The acoustic receivers in this receiver array were utilized in addition to the initial five receivers in the range test study to record detections of sentinel range tags throughout the study period. The receiver moorings were composed of concrete cylinders $(\sim 62 \mathrm{~kg})$ as the anchors connected to two $28-\mathrm{cm}$ trawl floats by a 3-m length of 1.1-mm polypropylene rope with inline nylon swivels. Receivers were attached midway along the 


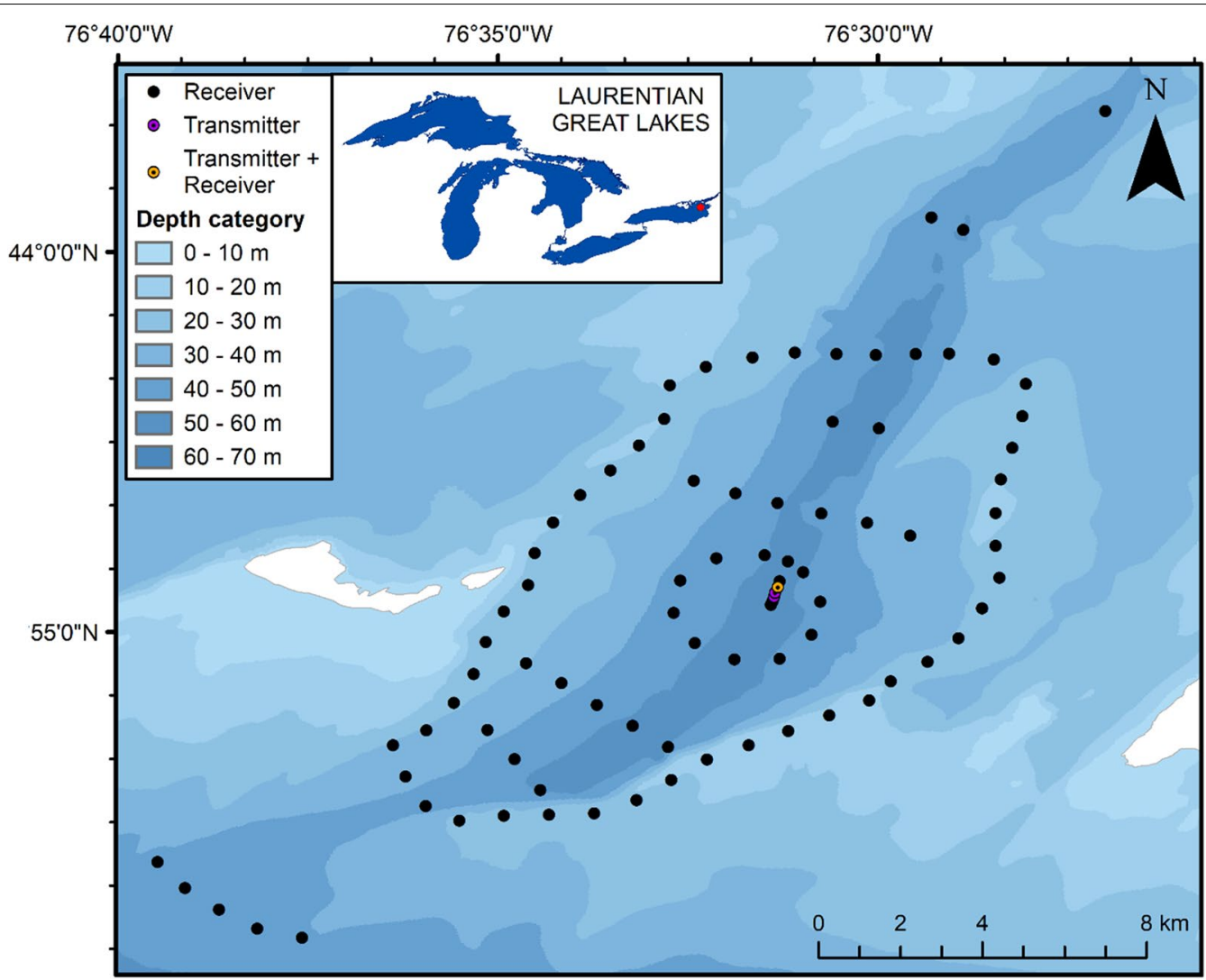

Fig. 1 Bathymetry and location of the tag and receiver moorings in northeastern Lake Ontario. Red circle in map inset signifies location of study site within the Laurentian Great Lakes. See Fig. 2 for fine-scale tag locations

rope with the hydrophone pointing upwards to be suspended $\sim 2 \mathrm{~m}$ above the lake bottom. An approximately 30-m weighted rope was attached to the concrete anchor at one end and a cinder block at the other end to serve as a drag line for grappling when retrieving the receivers for download. Receivers deployed for the duration of the study were all situated below the thermocline. All range tags were removed from the system in May 2016.

\section{Data analysis}

The complete receiver array, including the 85 receivers from the bloater telemetry project and the five receivers for range testing, was deployed from 22 October, 2015 to 23 May, 2016 ( 215 days). To ensure consistency across detection distances and probabilities, only detections for these dates were used in analyses. To verify that DE was not unduly biased by external factors affecting the performance of acoustic receivers, we evaluated receiver performance in relation to noise levels and sources following methods described by Simpfendorfer et al. [14]. Noise levels were determined by calculating a metric that estimates the amount and source of noise by comparing the expected number of pings based on synchronization intervals in the receiver's metadata to the actual number of pings recorded by the receiver. Briefly, ambient noise resulting from the environment and tag collisions from the presence of tagged fish was unlikely to have significantly impacted receiver performance or influenced DE measures (see Additional file 1).

\section{Spatial variability in detection efficiency}

To examine spatial variability in DE across tag types and depths, detection data were separated into five categories: deep V9, shallow V9, deep V13, deep V16, and shallow V16, where deep refers to tags at $\sim 50-\mathrm{m}$ depth and shallow refers to tags at $\sim 11$-m depth. Analyses were performed separately for each tag category. For each tag and receiver combination $(n=720)$, DE was calculated for each day of deployment by dividing the number of detections by the expected number of transmissions per day (48 for a nominal transmission interval of 1800 s). Daily $\mathrm{DE}$ was used to estimate DE for the entire study period using generalized additive mixed models (GAMMs) to explain the $\mathrm{DE}$ as a function of the two-dimensional distance between tags and receivers. GAMMs use non-parametric smoothing functions to describe nonlinear trends 


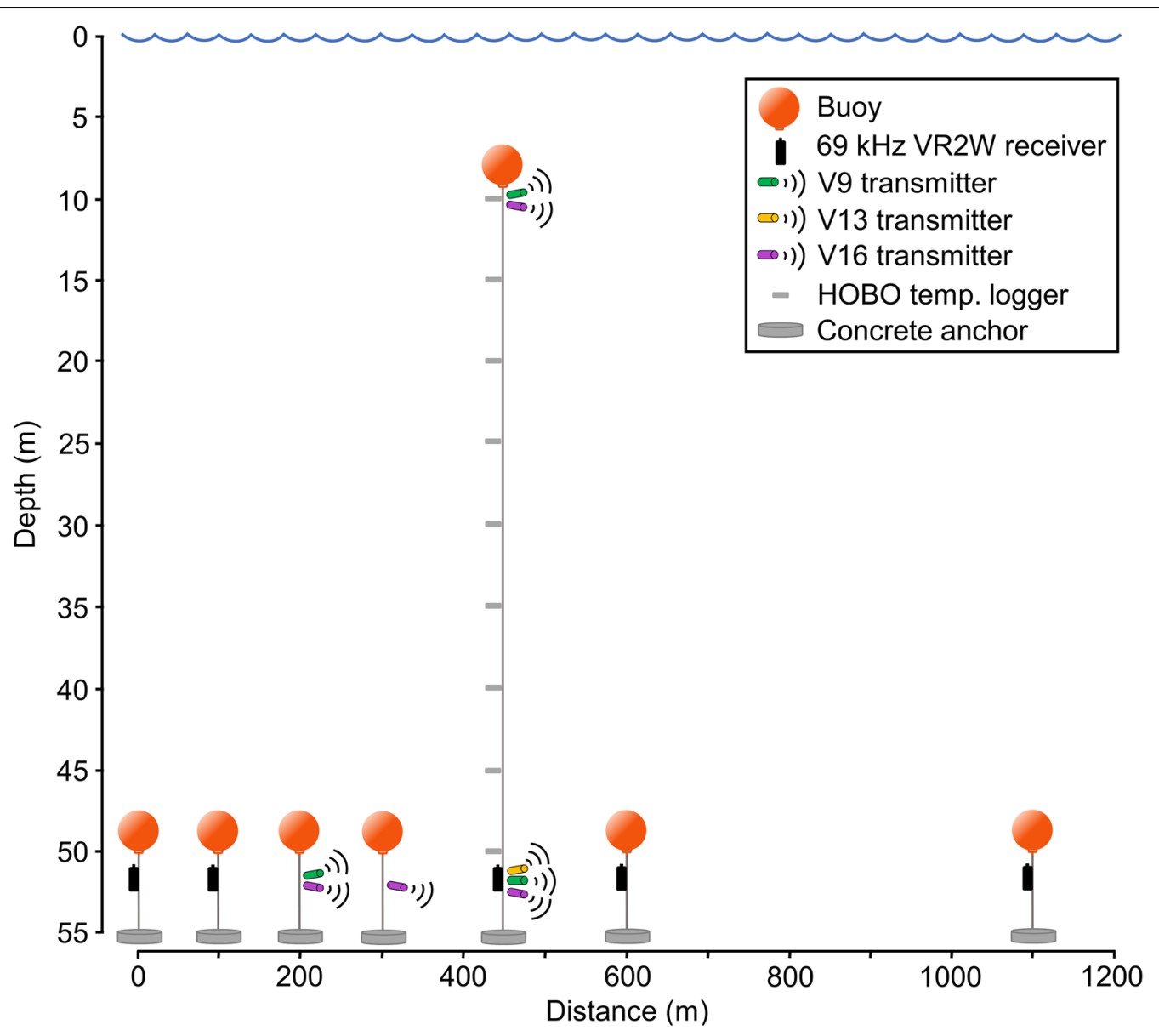

Fig. 2 Design of tag and receiver moorings deployed in the center of the Lake Ontario receiver array. Tags represent the four groups of tag deployments consisting of V9 (green), V13 (yellow), and V16 (purple) tags. See Fig. 1 for locations

Table 1 Summary of detections for sentinel range tags deployed in northeastern Lake Ontario from 22 October, 2015 to 23 May, 2016 ( 215 days)

\begin{tabular}{|c|c|c|c|c|c|c|c|c|}
\hline Tag & Type & Station & Depth (m) & Total detections & Detections. day ${ }^{-1}$ & $\begin{array}{l}\text { Detections.day } \\
{ }^{-1} \cdot \text { receiver }^{-1}\end{array}$ & Total receivers & $\begin{array}{l}\text { Max distance } \\
\text { detected }(\mathbf{k m})(\mathbf{k m}) \\
(\mathbf{k m})\end{array}$ \\
\hline 1 & V9 & 1 & 50 & 78,562 & $365.4 \pm 123.0$ & $4.9 \pm 11.1$ & 48 & 5.9 \\
\hline 2 & V9 & 3 & 50 & 75,942 & $353.2 \pm 118.1$ & $4.7 \pm 11.3$ & 49 & 5.9 \\
\hline 3 & V9 & 3 & 10 & 49,207 & $228.9 \pm 65.4$ & $3.1 \pm 9.4$ & 41 & 6.4 \\
\hline 4 & V13 & 3 & 50 & 92,054 & $428.2 \pm 140.1$ & $5.7 \pm 11.8$ & 67 & 8.2 \\
\hline 5 & V16 & 1 & 50 & 127,242 & $591.8 \pm 203.2$ & $7.9 \pm 13.2$ & 71 & 7.8 \\
\hline 6 & V16 & 2 & 50 & 121,028 & $562.9 \pm 194.1$ & $7.5 \pm 13.2$ & 71 & 8.0 \\
\hline 7 & V16 & 3 & 50 & 113,388 & $527.4 \pm 178.6$ & $7.0 \pm 12.9$ & 67 & 7.1 \\
\hline 8 & V16 & 3 & 10 & 112,000 & $520.9 \pm 162.5$ & $6.9 \pm 12.5$ & 74 & 9.3 \\
\hline
\end{tabular}

Detections $\cdot$ day $^{-1}$ represents the average number of detections per day across all 75 unique receivers that tags were detected on (mean \pm standard deviation), whereas detections day $^{-1}$.receiver ${ }^{-1}$ represents the average number of detections per day of a tag at each of the 75 receivers (mean \pm standard deviation). Total receivers is the total number of unique receivers that the tag was detected on for the duration of the study 
between predictor and response variables [29, 30]. The gamm function in the R package 'mgcv' fits a smoothing curve through the data using regression splines and was used to fit all GAMMs as it allows for autocorrelation and variance structures and random effects [31]. A primary challenge in range analysis is selecting a model that can accurately represent the DE profiles that are characteristic of range studies [10]. While many range studies have used a variety of linear and nonlinear models to describe DE and DR [10, 21, 28], we chose to implement GAMMs in part because of their ability to accommodate decreased DE at distances typically affected by CPDI as well as the above-listed benefits. However, we acknowledge that GAMMs are limited by a propensity to overfit and we have aimed to mitigate this issue by implementing smoothness selection to optimize smoothness parameters. GAMMs are also limited by a tendency to produce $p$ values that are biased low. We controlled for heterogeneity in the data by including tag-receiver combinations as a random effect with one intercept for each tagreceiver combination. A first-order auto-regressive moving average (ARMA) correlation structure was included in the model to account for temporal autocorrelation between detections on adjacent days nested within each tag-receiver combination. The distance covariate was fit with a penalized regression spline smoother to reduce the potential of overfitting the data when estimating the DE between sampled distances. A common occurrence in acoustically reflective environments is close proximity detection interference (CPDI), which is defined as a low DE for tags in close proximity to the receiver with peak DE occurring at an intermediate distance from the receiver [32,33]. To minimize the underfitting bias of smaller distances closer to the receiver where CPDI may occur, the largest appropriate basis dimension $(k)$ was selected for the distance smoother in each model following recommendations from the choose.k and gam. check functions in R as well as Sóskuthy [34]. The gam. check function in the R package 'mgcv' was used to assess model fit by visually evaluating residual plots and running diagnostic tests to ensure adequate basis dimensions for each smooth [31]. The GAMM results were used to predict an overall DE for distances from 100 to $7000 \mathrm{~m}$ in $1-\mathrm{m}$ increments. Model predicted DE was used to create an overall range curve across distance for the duration of the study.

\section{Temporal variability in detection efficiency}

To examine temporal variability in DE across the five tag categories, the distance GAMMs that were previously fit for the entire study period were used to predict three distances at which DE corresponded to mean rates of $0.25,0.50$, and $0.75\left(D_{0.25}, D_{0.50}, D_{0.75}\right)$ for each tag category. These three distances were calculated for each tag category to determine relevant distances that would be equivalent to the same mean $\mathrm{DE}$ across tag categories. The following analyses were conducted individually for each tag category. Detection data were grouped by day and modeled using GAMMs to create a single DE curve across distance for each day (215 days) of the study. All GAMMs were fit following the same methods described above. Model coefficients for each daily GAMM were used to estimate sentinel tag DE for the corresponding day at each of the three previously calculated distances $\left(\mathrm{DE}_{\mathrm{D} 0.25}, \mathrm{DE}_{\mathrm{D} 0.50}, \mathrm{DE}_{\mathrm{D} 0.75}\right)$. The $\mathrm{DE}_{\mathrm{D} 0.25}, \mathrm{DE}_{\mathrm{D} 0.50}$, and $\mathrm{DE} \mathrm{D}_{0.75}$ were grouped by week to calculate the mean and standard error of DE and examine overall trends in DE through time.

\section{Effect of environmental variables on detection efficiency}

The following methods were conducted individually for each tag type (V9, V13, V16) to analyze and facilitate comparison of the impact of environmental variables on $\mathrm{DE}$ among tag types. For each tag and receiver combination, DE was calculated for each day of deployment (8 tags $\times 90$ receivers $\times 215$ days $=154,800$ estimated daily $\mathrm{DE})$.

Environmental data were obtained from online databases and multiple instruments deployed in the study site to examine the effects of each environmental variable on DE. Daily mean temperatures at 10 and $50 \mathrm{~m}$ were calculated from measurements taken every hour by $\mathrm{HOBO}$ Pendant loggers deployed at various depths in the study site near the sentinel tags. Daily surface water velocity and ice thickness data were calculated from hourly readings taken at the center of the receiver array archived in the Great Lakes Observing System (GLOS) online database (http://data.glos.us/glcfs/). The daily difference in water temperature between 10 and $50 \mathrm{~m}$-the depth range between the shallow and deep tags-was used to calculate a variable that represented the strength of the thermocline by subtracting the temperature at $50 \mathrm{~m}$ from the temperature at $10 \mathrm{~m}$.

To evaluate possible drivers of temporal patterns in DE, a suite of environmental variables (henceforth covariates) were considered: surface water velocity, ice thickness, water temperature at $10 \mathrm{~m}$, water temperature at $50 \mathrm{~m}$, thermocline strength, receiver depth, tag depth, depth difference between tag and receiver, distance between tag and receiver, week, and month. Since tagged fish were present in the system during range testing, we also included the number of fish detections as a covariate to account for any possible variability in DE caused by an influx of fish transmissions interfering with receipt of range tag transmissions. We assessed collinearity of these covariates using Pearson's pairwise correlation 
coefficient to verify independence prior to inclusion in additional analyses. Highly collinear pairs included water temperature at 10 and $50 \mathrm{~m}$ (pairwise $\mathrm{cc}=1.0$ ), water temperature at $10 \mathrm{~m}$ and month (pairwise $\mathrm{cc}=0.8$ ), water temperature at $50 \mathrm{~m}$ and month (pairwise $\mathrm{cc}=0.8$ ), week and month (pairwise $c c=0.9$ ), week and water temperature at $50 \mathrm{~m}$ (pairwise $\mathrm{cc}=0.7$ ), and receiver depth and distance between tag and receiver (pairwise $\mathrm{cc}=-0.7$ ). As such, water temperature at $10 \mathrm{~m}$, water temperature at $50 \mathrm{~m}$, month, and week were considered as a single covariate represented by water temperature at $50 \mathrm{~m}$ in further analyses. Receiver depth and distance between tag and receiver were also considered a single covariate represented by distance from receiver. Daily averages of the remaining covariates were linked to the respective daily DE.

GAMMs were used to examine non-linear trends in time series of $\mathrm{DE}$ as a function of surface water velocity, ice thickness, water temperature at $50 \mathrm{~m}$, thermocline strength, tag depth, depth difference between tag and receiver, number of fish detections, and distance between tag and receiver, all of which were continuous variables except for tag depth. All GAMMs were fit following the methods described in above-listed analyses. The optimal ARMA correlation structure was determined using the auto.arima function in the $\mathrm{R}$ package 'forecast' and the highest order correlation structure that produced the smallest Akaike Information Criterion (AIC) while allowing for model convergence was used [35].

To account for the influence of distance on the trajectory of the smooth for each of the environmental covariates, we included interaction terms for distance and each environmental covariate in addition to the main effect smooth terms for each variable [34]. We used 'tensor product interactions' in the GAMM, which are conceptually very similar to interactions in linear models [34]. A pool of candidate models was created with selected model parameters matching hypothesized explanatory variables. AIC model selection was used to identify the best fitting GAMM. Adjusted $R^{2}$ is defined as the variation explained by only the independent variables that affect the dependent variable. Statistical analyses were performed using $R$ version 3.5.2 [36], and statistical significance was assumed at $\alpha=0.05$.

\section{Results}

\section{Detection summary}

A total of 769,423 acoustic transmissions were detected from eight stationary acoustic tags on 75 acoustic receivers in northeastern Lake Ontario from 22 October, 2015 to 23 May, 2016 (Fig. 1; Table 1). The other 15 receivers in the array did not record any detections of the tags as they were beyond detection range. Potential false detections were identified by calculating the transmission interval between sequential detections of tags on each receiver in relation to the minimum transmission interval of the tags $(1750 \mathrm{~s})$. The effect was considered negligible $(0.1 \%)$. A nominal transmission delay of $1800 \mathrm{~s}$ resulted in an expected 48 transmissions for each acoustic tag per day. The average number of detections per day for each of the 75 receivers was similar within tag types with shallow V9 tags exhibiting the lowest number of daily detections $\left(3.1 \pm 9.4\right.$ detections $\cdot$ day $\left.^{-1}\right)$ and deep V16 tags exhibiting the highest number of daily detections $(7.9 \pm 13.2$ detections.day ${ }^{-1}$ ) (Table 1). The shallow V9 and V16 tags were detected at a greater maximum distance $(6.4 \mathrm{~km}$ and $9.3 \mathrm{~km}$, respectively) than their deeper counterparts and had a lower number of daily detections $(3.1 \pm 9.4$ and $6.9 \pm 12.5$ detections $\cdot$ day $^{-1}$, respectively) than the deep tags. The maximum distance detected ranged from $5.9 \mathrm{~km}$ to $9.3 \mathrm{~km}$ (Table 1) although detections at these distances occurred infrequently, resulting in a DE of nearly zero.

\section{Spatial variability in detection efficiency}

$\mathrm{DE}$ of the sentinel range tags in Lake Ontario displayed an overall negative relationship with distance between the tag and receiver for the duration of the study (Fig. 3; Table 2). The effects of CPDI were visible in the DE curve for the deep V16 tags as indicated by low DE at distances closer to the receiver (Fig. 3). Although the DE curves for the deep V9, deep V13, and shallow V16 tags did not exhibit CPDI, they featured fluctuations in DE at distances from 0 to $1000 \mathrm{~m}$ that are atypical of DE curves in environments not impacted by CPDI (Fig. 3). The shallow V9 tag did not experience CPDI or an abnormal DE profile and had the highest DE (0.97) at the distance closest to the receiver $(100 \mathrm{~m})$ (Fig. 3; Table 2). DE and DR increased with higher power output of the tags, however, the size of the region impacted by CPDI or abnormal DE also increased with higher power output (Fig. 3). Beyond the distance impacted by CPDI and fluctuating DE, shallow tags consistently had lower DE than deep tags of the same power output (Table 2). All model smoothing splines were significant. Model fit estimated by adjusted $R^{2}$ ranged from 0.824 to 0.895 .

\section{Temporal variability in detection efficiency}

Estimated DE ${ }_{\mathrm{D} 0.25}, \mathrm{DE}{ }_{\mathrm{D} 0.50}$, and DE 0.75 fluctuated through time displaying a similar overall trend across all tag categories (Fig. 4). Weekly DE was relatively variable during the first month of the study and then decreased in early December through February, increased rapidly through March, remained relatively constant in April and then fluctuated more in May (Fig. 4). Weekly DE was less variable in shallow tags (maximum range 0.53) than in 


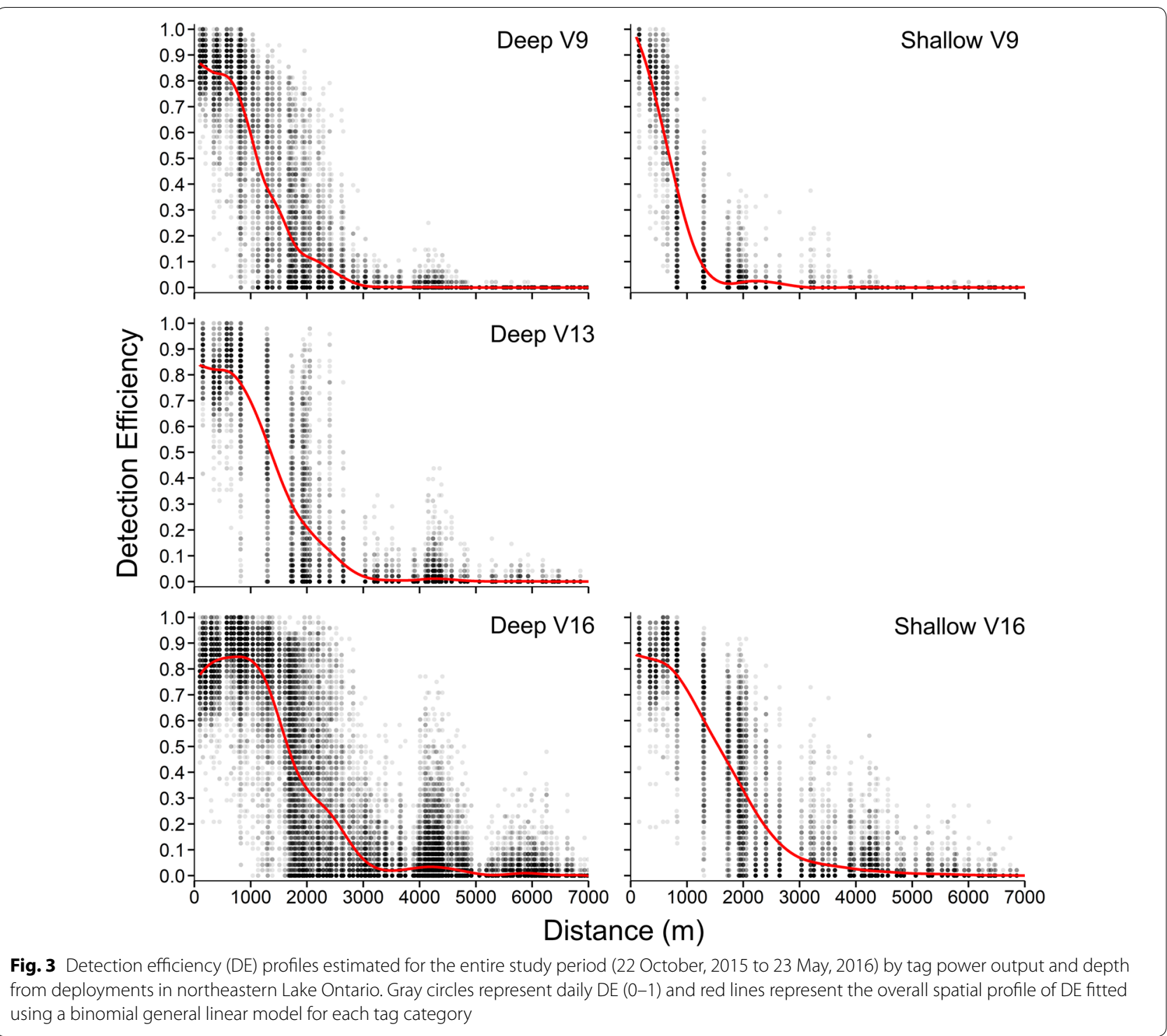

deeper tags (maximum range 0.75 ), which is especially notable during the last 5 weeks of 2015 and first 4 weeks of 2016 (Fig. 4). Tags with higher power output exhibited similar variability in DE (deep V16 maximum range 0.75 ) compared to tags with lower power output (deep V9 maximum range 0.73; Fig. 4). Daily DE was less variable at the short and long distances for a given tag-receiver with increased variation of $\mathrm{DE}$ at the intermediate distances (Fig. 4). For instance, maximum range of DE for the deep V9 tags at the shortest, intermediate, and longest distance was $0.55,0.73$, and 0.67 , respectively. The stocking of 70 tagged bloaters showed no evident impact on weekly DE trends (e.g., Figure 4; weeks 48-49). Model fit for all daily GAMMs estimated by adjusted $R^{2}$ ranged from 0.732 to 0.997 and was higher than 0.8 for $98 \%$ of models.

\section{Effect of environmental variables on detection efficiency}

Environmental conditions experienced throughout the study period were variable for surface water velocity (range: $0.02-0.57 \mathrm{~m} \mathrm{~s}^{-1}$ ), water temperature at $10 \mathrm{~m}$ (range: $0.25-13.21^{\circ} \mathrm{C}$ ), water temperature at $50 \mathrm{~m}$ (range: $0.39-12.86{ }^{\circ} \mathrm{C}$ ), and thermocline index (range: - 1.493.05) whereas ice thickness (range: $0-0.30 \mathrm{~m}$ ) only varied during the months of January, February, and March (Fig. 5). The best fitting GAMMs as identified by the lowest AIC scores were the full model excluding tag depth for the V9 and V16 tags and the full model excluding tag depth, depth difference between tag and receiver, and the interaction between distance and depth difference for the V13 tag (Table 3; see Additional file 1 Table S1 for all models). All smooth and interaction terms in the best fitting models were significant. Partial effects of individual 
Table 2 Detection efficiencies (0-1) \pm standard error for various tag power outputs and depths at set distances ranging from 100 to $2400 \mathrm{~m}$ in Lake Ontario

\begin{tabular}{|c|c|c|c|c|c|}
\hline \multirow{2}{*}{$\begin{array}{l}\text { Distance } \\
\text { (m) }\end{array}$} & \multicolumn{5}{|c|}{ Tag category } \\
\hline & V950 m & V9 $11 \mathrm{~m}$ & V13 $50 \mathrm{~m}$ & $\mathrm{~V} 1650 \mathrm{~m}$ & $\mathrm{~V} 1611 \mathrm{~m}$ \\
\hline 100 & $0.87 \pm 0.03$ & $0.97 \pm 0.06$ & $0.84 \pm 0.04$ & $0.78 \pm 0.04$ & $0.85 \pm 0.03$ \\
\hline 200 & $0.85 \pm 0.02$ & $0.91 \pm 0.04$ & $0.83 \pm 0.03$ & $0.80 \pm 0.02$ & $0.84 \pm 0.03$ \\
\hline 300 & $0.84 \pm 0.02$ & $0.85 \pm 0.03$ & $0.82 \pm 0.02$ & $0.82 \pm 0.02$ & $0.84 \pm 0.02$ \\
\hline 400 & $0.83 \pm 0.02$ & $0.77 \pm 0.03$ & $0.82 \pm 0.02$ & $0.84 \pm 0.02$ & $0.83 \pm 0.02$ \\
\hline 500 & $0.83 \pm 0.02$ & $0.68 \pm 0.03$ & $0.82 \pm 0.02$ & $0.85 \pm 0.02$ & $0.82 \pm 0.02$ \\
\hline 600 & $0.81 \pm 0.02$ & $0.59 \pm 0.03$ & $0.81 \pm 0.02$ & $0.86 \pm 0.02$ & $0.80 \pm 0.02$ \\
\hline 700 & $0.78 \pm 0.02$ & $0.50 \pm 0.02$ & $0.80 \pm 0.02$ & $0.86 \pm 0.01$ & $0.78 \pm 0.02$ \\
\hline 800 & $0.73 \pm 0.02$ & $0.40 \pm 0.02$ & $0.77 \pm 0.02$ & $0.85 \pm 0.02$ & $0.75 \pm 0.02$ \\
\hline 900 & $0.67 \pm 0.02$ & $0.32 \pm 0.03$ & $0.74 \pm 0.03$ & $0.83 \pm 0.02$ & $0.72 \pm 0.02$ \\
\hline 1000 & $0.59 \pm 0.02$ & & $0.70 \pm 0.03$ & $0.81 \pm 0.02$ & $0.68 \pm 0.03$ \\
\hline 1100 & $0.51 \pm 0.02$ & & $0.65 \pm 0.03$ & $0.78 \pm 0.02$ & $0.64 \pm 0.03$ \\
\hline 1200 & $0.44 \pm 0.02$ & & $0.59 \pm 0.03$ & $0.76 \pm 0.02$ & $0.60 \pm 0.03$ \\
\hline 1300 & $0.38 \pm 0.02$ & & $0.53 \pm 0.03$ & $0.73 \pm 0.02$ & $0.56 \pm 0.03$ \\
\hline 1400 & $0.34 \pm 0.02$ & & $0.47 \pm 0.03$ & $0.70 \pm 0.02$ & $0.52 \pm 0.03$ \\
\hline 1500 & $0.30 \pm 0.02$ & & $0.42 \pm 0.03$ & $0.65 \pm 0.02$ & $0.48 \pm 0.02$ \\
\hline 1600 & $0.25 \pm 0.02$ & & $0.36 \pm 0.03$ & $0.58 \pm 0.02$ & $0.45 \pm 0.02$ \\
\hline 1700 & & & $0.31 \pm 0.02$ & $0.50 \pm 0.02$ & $0.41 \pm 0.02$ \\
\hline 1800 & & & $0.27 \pm 0.02$ & $0.42 \pm 0.02$ & $0.37 \pm 0.02$ \\
\hline 1900 & & & & $0.35 \pm 0.02$ & $0.33 \pm 0.02$ \\
\hline 2000 & & & & $0.32 \pm 0.02$ & $0.29 \pm 0.02$ \\
\hline 2100 & & & & $0.30 \pm 0.02$ & $0.25 \pm 0.02$ \\
\hline 2200 & & & & $0.30 \pm 0.02$ & \\
\hline 2300 & & & & $0.28 \pm 0.02$ & \\
\hline 2400 & & & & $0.26 \pm 0.02$ & \\
\hline
\end{tabular}

Detection efficiencies were estimated from GAMMs calculated for each tag category using detection data from 22 October, 2015 to 23 May, 2016

environmental variables included in the best fitting models indicate that distance had the largest effect on DE for V9, V13, and V16 tags and the effect of individual environmental variables, although less influential, is similar among tag types (Fig. 6). Estimates of summed effects of the interactions from the best fitting GAMMs for V9 and V16 tags revealed that the extent to which DE declines with distance is influenced by environmental variables (Fig. 7). As the distance between tag and receiver increases, thermocline, water velocity, and ice thickness had a diminishing effect on DE (Fig. 7a-f) and water temperature had an increasing effect on DE (Fig. $7 \mathrm{~g}, \mathrm{~h}$ ). Collinear variables that were not included as covariates in the models but were also significant were water temperature at $10 \mathrm{~m}$, week, month, and receiver depth. Model fit for the best fitting GAMMs for each tag type estimated by adjusted $R^{2}$ ranged from 0.908 to 0.916 .

Maximum recorded detection distance occurred once (26 October, 2015) for the shallow tags at $9.3 \mathrm{~km}$ when surface water velocity and temperature difference between 10 and $50 \mathrm{~m}$ were $0.04 \mathrm{~m} \cdot \mathrm{s}^{-1}$ and $0.09{ }^{\circ} \mathrm{C}$, respectively, relative to the period averages of $0.10 \pm 0.08 \mathrm{~m} \cdot \mathrm{s}^{-1}$ and $0.22 \pm 0.69^{\circ} \mathrm{C}$. Similarly, the maximum recorded detection distance occurred twice $(26$ October, 2015 and 7 December, 2015) for the deep tags at $8.2 \mathrm{~km}$ when surface water velocity and temperature difference between 10 and $50 \mathrm{~m}$ averaged $0.04 \pm 0.00 \mathrm{~m} \cdot \mathrm{s}^{-1}$ and $0.13 \pm 0.05{ }^{\circ} \mathrm{C}$, respectively. Most detections at maximum range occurred when ice was not present, the thermal gradient was relatively small, and surface water velocity was low.

\section{Discussion}

The present study demonstrated that the probability of a receiver detecting a transmission from an acoustic tag in Lake Ontario varies both spatially and temporally and is influenced by environmental conditions. The primary factor that influences DE and DR in acoustic telemetry studies is the distance between tag and receiver due to the physics of sound propagation in water [10]. The power output of the tag also has a strong impact on DE and DR as tags with high power are inherently able to transmit stronger sound signals that can travel greater distances [8]. Finally, an assortment of biotic and abiotic factors in the environment can influence the rate of energy attenuation and sound absorption as the signal travels through water [9]. Interestingly, we found that the effect of distance on DE and DR varies across environment variables and tag types, demonstrating the complex interaction of multiple factors that influence DE and DR.

This study reports higher DE at greater tag-receiver distances than many previously published studies as well as a greater maximum detection distance. For example, we detected transmissions from our tags at a maximum distance of $9.3 \mathrm{~km}$; whereas many studies report maximum detection distance below $1 \mathrm{~km}[20,23,37]$. The main reason for these differences is the relatively less dense and less dynamic freshwater environment of Lake Ontario in comparison to many marine or coral reef settings. Similar to our findings, Hayden et al. [10] observed a maximum detection distance of $11.8 \mathrm{~km}$ in a large temperate freshwater lake. Large detection distances may add a level of complexity to analysis of telemetry data from tagged animals due to increased uncertainty associated with position estimates. All of the tags in this study exhibited similar relationships between DE and distance, and DR increased as power output increased.

Depth can be an important factor in telemetry studies because it can increase Euclidean distances between a tag and receiver and transmission signals may cross vertically heterogeneous or stratified layers (e.g., thermocline). 


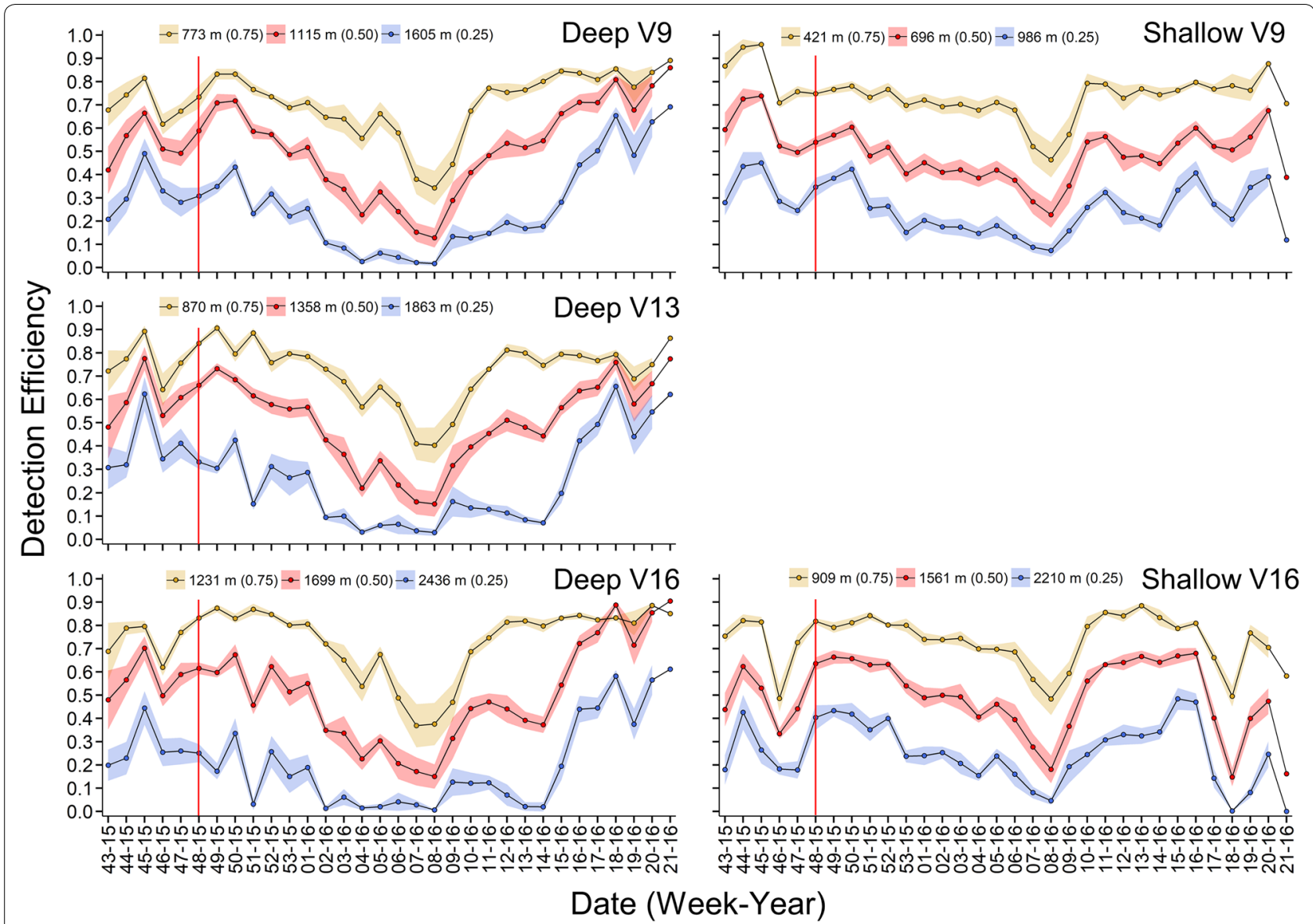

Fig. 4 Detection efficiency (DE) time series estimated for three distances $\left(D_{0.25}, D_{0.50}, D_{0.75}\right)$ by tag type and depth from deployments in northeastern Lake Ontario. Circles represent weekly DE (0-1) and ribbons signify standard error for each tag category. Vertical red line indicates date of release of tagged fish. Date is shown in the format of week-year

Relatively few range studies have incorporated tag and receiver depth as a variable in their analyses; those that have are often at relatively shallow depths of $<20 \mathrm{~m}[23$, $33]$. DE in our study was lower for shallow tags compared to deep tags of the same power output, which may be a result of greater overlap of the original signal and reflection of signals created by transmissions from shallow tags traveling across depth. Similarly, Scherrer et al. [33] observed greater DE and DR for tags at depth $(15 \mathrm{~m})$ than for tags closer to the surface $(1 \mathrm{~m})$. In contrast, Cagua et al. [23] found that increasing proximity of the tag to the bottom in a coral reef habitat significantly reduced the probability of detecting the tag. Inconsistencies in the effects of depth across studies may indicate that the effects of equipment depth-both tags and receivers-are dependent on the characteristics of the environment (e.g., local bathymetry, environmental noise, bottom composition, etc.). In reef environments, there is more environmental noise closer to the benthos that interferes with $\mathrm{DE}$ as a result of noisy marine animals (e.g., snapping shrimp, parrotfishes), as well as irregular bottom topography. In a freshwater environment, as demonstrated in this study, levels of biological noise at depth are expected to be limited, and deeper waters may provide a barrier to the effects of some environmental conditions (e.g., wind, precipitation) that could impact DE. Different bottom compositions can also result in reflective or absorptive environments, thus increasing or reducing the amount of noise in a system. Many telemetry studies focus on surface-oriented species (e.g., salmon) and most receiver deployments are bottom-oriented, thus it is important to consider the influence of tag and receiver depth on gear performance. Receivers positioned higher in the water column may also introduce issues with receiver movement, tilt, and entanglement with longer mooring lines, especially in open water systems. To reduce the potential effects of equipment depth on DE, telemetry studies should be designed based on the expected depth used by the study species and associated environmental structure or conditions that will impact DE. 

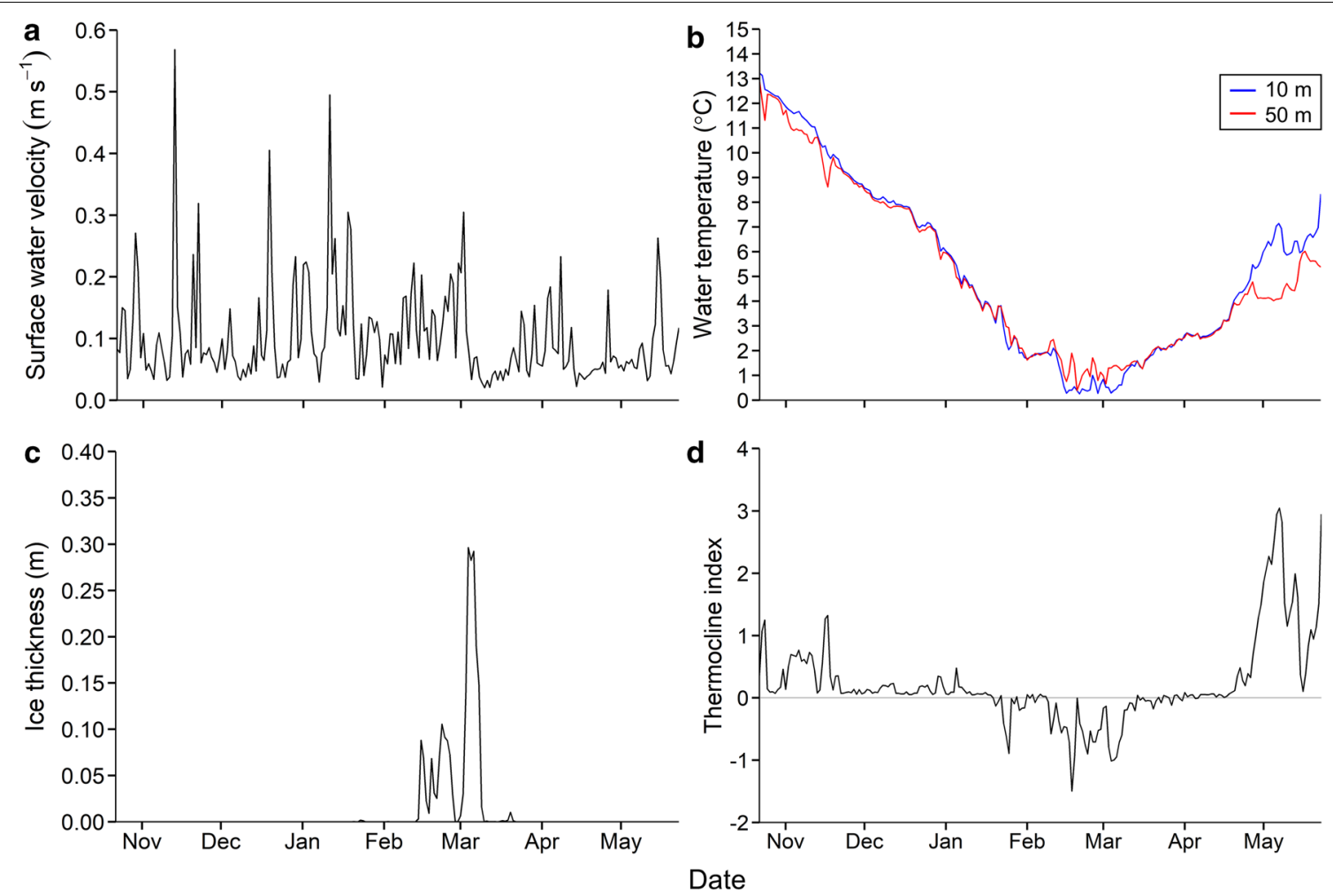

Fig. 5 Daily environmental variables for the entire study period (22 October, 2015 to 23 May, 2016): a surface water velocity $\left(\mathrm{m} \cdot \mathrm{s}^{-1}\right.$ ); b water temperature $\left({ }^{\circ} \mathrm{C}\right)$ at $10 \mathrm{~m}$ (blue) and $50 \mathrm{~m}($ red); $\mathbf{c}$ ice thickness $(\mathrm{m})$; $\mathbf{d}$ thermocline index

Table 3 Summary information for the best fitting five candidate models (including global model) summarizing the detection efficiency (DE) of V9, V13, and V16 tags deployed in northeastern Lake Ontario from 22 October, 2015 to 23 May, 2016 (215 days) as a function of environmental variables

\begin{tabular}{|c|c|c|c|c|c|c|c|c|c|}
\hline \multirow[t]{2}{*}{ Model } & \multicolumn{3}{|l|}{ V9 } & \multicolumn{3}{|l|}{ V13 } & \multicolumn{3}{|l|}{ V16 } \\
\hline & AIC & $\triangle A I C$ & $\operatorname{Adj} . R^{2}$ & AIC & $\triangle \mathrm{AIC}$ & $\operatorname{Adj} . R^{2}$ & AIC & $\triangle \mathrm{AIC}$ & Adj. $R^{2}$ \\
\hline $\begin{array}{l}D E \sim \mathrm{ti}(D, t h)+\mathrm{ti}(D, v)+\mathrm{ti}(D, i)+\mathrm{ti}(D, t)+ \\
\mathrm{ti}(D, d)+\mathrm{ti}(D, f)+\mathrm{s}(D)+\mathrm{s}(\mathrm{th})+\mathrm{s}(v)+\mathrm{s}(i)+ \\
\mathrm{s}(t)+\mathrm{s}(d)+\mathrm{s}(f)+\operatorname{tag}\end{array}$ & $-33,302.38$ & 13.31 & 0.908 & $-10,256.59^{*}$ & 15.31 & 0.916 & $-38,410.15$ & 13.44 & 0.907 \\
\hline $\begin{array}{l}D E \sim \mathrm{ti}(D, t h)+\mathrm{ti}(D, v)+\mathrm{ti}(D, i)+\mathrm{ti}(D, t)+ \\
\mathrm{ti}(D, d)+\mathrm{ti}(D, f)+s(D)+s(t h)+s(v)+s(i)+ \\
s(t)+s(f)+\operatorname{tag}\end{array}$ & $-33,290.74$ & 24.95 & 0.903 & $-10,262.80^{*}$ & 9.10 & 0.916 & $-38,417.44$ & 6.15 & 0.907 \\
\hline $\begin{array}{l}D E \sim \mathrm{ti}(D, t h)+\mathrm{ti}(D, v)+\mathrm{ti}(D, i)+\mathrm{ti}(D, t)+ \\
\mathrm{ti}(D, d)+\mathrm{ti}(D, f)+\mathrm{s}(D)+\mathrm{s}(\mathrm{th})+\mathrm{s}(v)+\mathrm{s}(i)+ \\
\mathrm{s}(t)+\mathrm{s}(d)+\mathrm{s}(f)\end{array}$ & $-33,315.69$ & 0 & 0.908 & $-10,256.59$ & 15.32 & 0.916 & $-38,423.59$ & 0 & 0.908 \\
\hline $\begin{array}{l}D E \sim \mathrm{ti}(D, t h)+\mathrm{ti}(D, v)+\mathrm{ti}(D, i)+\mathrm{ti}(D, t)+ \\
\mathrm{ti}(D, f)+\mathrm{s}(D)+\mathrm{s}(t h)+\mathrm{s}(v)+\mathrm{s}(i)+\mathrm{s}(t)+ \\
\mathrm{s}(f)+\operatorname{tag}\end{array}$ & $-33,183.61$ & 132.08 & 0.876 & $-10,271.90^{*}$ & 0 & 0.916 & $-38,386.14$ & 37.45 & 0.902 \\
\hline $\begin{array}{l}\mathrm{DE} \sim \mathrm{ti}(D, t h)+\mathrm{ti}(D, v)+\mathrm{ti}(D, i)+\mathrm{ti}(D, f)+ \\
\mathrm{s}(D)+\mathrm{s}(\mathrm{th})+\mathrm{s}(v)+\mathrm{s}(i)+\mathrm{s}(t)+\mathrm{s}(f)+\operatorname{tag}\end{array}$ & $-33,302.38$ & 13.31 & 0.908 & $-10,256.59^{*}$ & 15.32 & 0.916 & $-38,410.15$ & 13.44 & 0.907 \\
\hline
\end{tabular}

DE is the daily probability of detecting an acoustic transmission. $s()$ indicates a smoother and ti() indicates a tensor product interaction. Environmental variables included were distance between tag and receiver $(D)$, thermocline strength $(t h)$, surface water velocity $(v)$, ice thickness $(i)$, temperature at $50 \mathrm{~m}(t)$, depth difference between receiver and tag $(d)$, number of fish detections $(f)$, and tag depth (tag). All models included an ARMA autocorrelation structure to account for temporal autocorrelation in data and tag-receiver combinations as a random effect. Akaike information criteria (AIC), delta AIC, and estimated adjusted coefficient of determination (Adj. $R^{2}$ ) are summarized for each model. The lowest AIC scores are italicized for each tag type to identify the best fitting model. An asterisk $(*)$ denotes models that did not include tag as a covariate due to the lack of tags present at more than one depth 
(See figure on next page.)

Fig. 6 Partial effects of nonlinear environmental variables on detection efficiency (DE) for each of the three best fitting generalized additive mixed models (GAMMs) for the V9, V13, and V16 tags, respectively. Environmental variables included are distance between tag and receiver ( $\mathrm{m}$ ), thermocline index, surface water velocity $\left(\mathrm{m} \cdot \mathrm{s}^{-1}\right)$, ice thickness $(\mathrm{m})$, temperature at $50 \mathrm{~m}\left({ }^{\circ} \mathrm{C}\right)$, number of fish detections, and depth difference between tag and receiver $(\mathrm{m})$. Thermocline index represents the strength of the thermocline where zero signifies thermal homogeneity and values departing from zero in either direction indicate an increasing thermal gradient. Positive values of depth difference indicate that the tag is shallower than the receiver whereas negative values indicate that the tag is deeper than the receiver. The $y$-axes represent the partial effect on DE and are shown in the format of $s$ (covariate, effective degrees of freedom). Shaded areas represent the $95 \%$ confidence interval around each smooth term

A notable difference in DE across tag categories was the variability at distances close to the receiver as a result of CPDI and abnormal fluctuations in DE. Although CPDI is a phenomenon that has recently been defined in aquatic acoustic telemetry literature [32], some studies have shown that the size of the radial region impacted by CPDI increases with power output and tag depth [32, 33]. The effect of CPDI may have been underestimated in this study as the minimum tag-receiver distance was $100 \mathrm{~m}$ and residual signal power, and thus the potential for CPDI, would increase at shorter distances. If unaccounted for, CPDI could lead to decreased performance of an acoustic telemetry array and the production of less reliable detection data that is misinterpreted during analysis. This may be particularly problematic for sedentary species or home-range studies, but less problematic for migratory species expected to move past a receiver as the tags would be detected prior to entry into the CPDI and post-exit. Researchers generally aim for the maximum possible DR and thus employ the most powerful tags the study species can physically (or ethically) accommodate [19], but the effects of CPDI on higher power output tags is worth further consideration in study design depending on the scale of the study, the resolution of data sought and the objectives.

The temporal variation observed in our study suggests that short-term range studies may not be representative of $\mathrm{DE}$ over longer time intervals, particularly in systems that have a lot of seasonal variation in environmental conditions, such as thermoclines and seasonal ice that vary within and between years. Over the 7-month study period, we observed a high degree of variability in DE that was inconsistent through time. Temporal trends were similar across tag types, indicating that variability in DE was caused by temporal changes in the study system rather than tag characteristics. Decreased DE during winter months may be a result of the noise created during periods of ice formation and break-up interfering with acoustic signal reception. Most range assessment studies have focused more on spatial variation [38] or have occurred over a shorter term that may not reveal the same magnitude of temporal variability $[39,40]$. As such, to identify periods of high and low DE in systems in temperate systems, like Lake Ontario, it may be necessary to deploy sentinel range tags for the entire duration of the telemetry study. The present study did not encompass a full year of data and it is possible that had greater seasonal variation been captured, the environmental covariates would have exhibited a stronger relationship with DE.

Models with the best fit for each tag type included the majority of covariates with all terms in the model being significant, suggesting that DE may be related to a combination of multiple biotic and abiotic parameters that can vary across spatial and temporal scales. Temporal variation in DE is largely influenced by changes in environmental conditions [21]. For instance, the low DE that was experienced during winter months is likely associated with a combination of lower water temperatures, an isothermal water column, increased ice cover, or other environmental changes that are characteristic of the winter season. Huveneers et al. [21] compiled a summary of the influences of environmental variables on DE from numerous range studies, illustrating the variability observed across studies. For instance, while some studies reported tag depth and wind speed as not being significant $[41,42]$, other studies reported a significant negative relationship [23] or a significant positive relationship [25] with DE.

Water temperature and thermal gradients have been found to impact DE due to environmental changes associated with water temperature (e.g., increased activity in ectothermic organisms) and the reflection and distortion of sound signals by thermal gradients [22, 43, 44]. Water temperature may be correlated with the presence of benthic organisms such as snapping shrimp in marine environments, the density of small biological organisms in the water column, or vegetation growth, some of which have been attributed to decreases in DE [42]. Although the effect appeared small, our study is consistent with others in finding that increased temperature and thermal stratification negatively impact DE. Huveneers et al. [21] reported four other range studies that assessed the effects of thermal stratification and all studies found a negative relationship with $\mathrm{DE}[23,26,41,45]$. The majority of our study period occurred when the lake was isothermal or a relatively weak thermal gradient was present. Unfortunately, these data do not encompass the summer season 

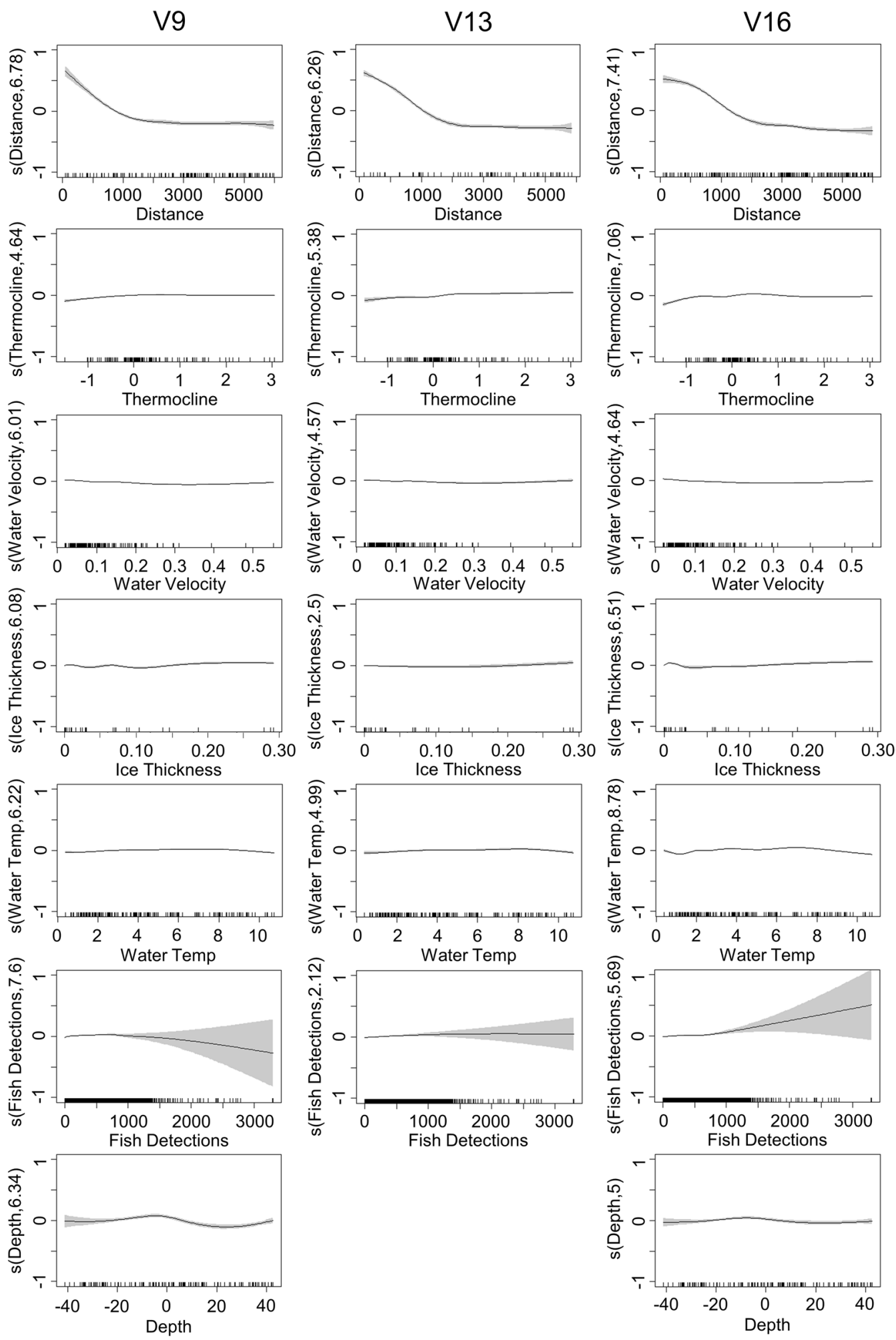


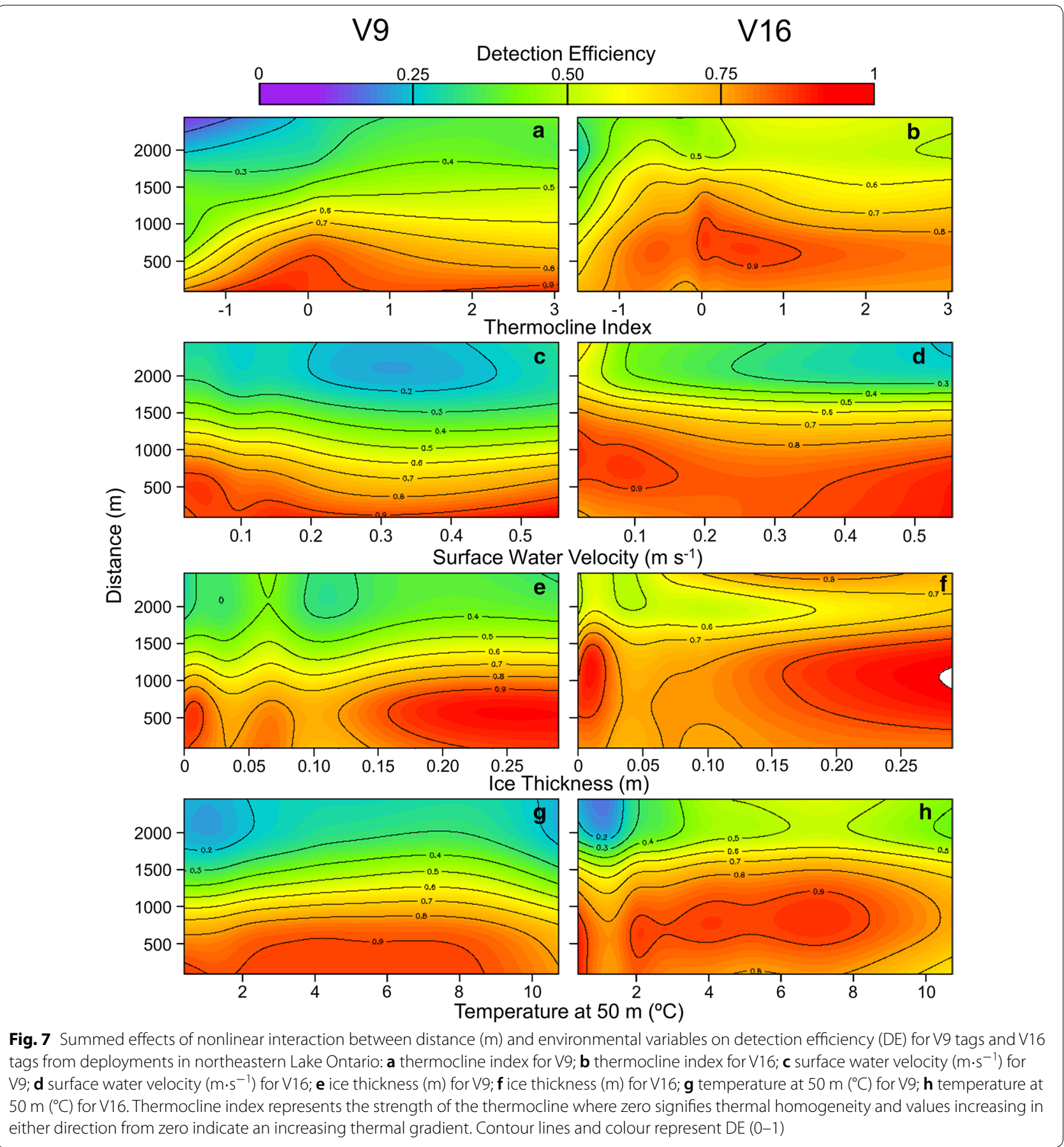

when thermal stratification is more pronounced; hence, we cannot directly comment on its effect, although we hypothesize the thermocline would result in a much stronger impact on DE. For example, Singh et al. [26] reported a $75 \%$ reduction in $\mathrm{DE}$ in water with a $5{ }^{\circ} \mathrm{C}$ temperature difference. The maximum temperature difference we observed in the water column during our study was $\sim 3{ }^{\circ} \mathrm{C}$, which is relatively small compared to the $\sim 15{ }^{\circ} \mathrm{C}$ temperature difference observed within our array in the summer. Since thermally stratified water columns can reflect and distort acoustic transmissions, it is especially important to consider the depth of receivers and the study animal where seasonal thermoclines may be present, such as the Great Lakes. Water temperature at $10 \mathrm{~m}$, week, and month were not directly examined due to collinearity with water temperature at $50 \mathrm{~m}$. 
Water temperature at $10 \mathrm{~m}$ would have the same effect as water temperature at $50 \mathrm{~m}$, with increased temperatures closer to the surface resulting in decreased DE. Temporal parameters such as week and month are often correlated with environmental variables in a system like Lake Ontario where seasonal environmental changes are prevalent. While we believe that our environmental variables captured the temporal trends in DE in Lake Ontario, week or month might be beneficial in identifying reduced receiver performance over time or the effects of other variables that might have a more linear trend such as a biofouling.

Surface water velocity is typically related to wind speed, wave height, and current, all of which are variables that have been previously examined in DE and range studies [14, 25, 27]. Wind speed, wave height, and current typically have either no effect or a negative relationship with DE $[27,45]$. In our study, there was an immediate decrease in DE as soon as water velocity approached $0.1 \mathrm{~m} \cdot \mathrm{s}^{-1}$. Environmental conditions that disturb the water's surface can alter sound signals. Under some circumstances, variables such as surface water velocity or ice thickness can decrease DE by distorting sound transmissions (e.g., tag pings). Alternatively, they can also cause reflection of transmissions downward through the water column to the receivers, which may increase DE. In our study, ice thickness had an interesting relationship with DE where DE was high when there is no ice, fluctuates at ice thicknesses of $0.02-0.12 \mathrm{~m}$, and then increases again when ice thickness exceeds $0.12 \mathrm{~m}$. Since most range assessment studies are conducted in tropical marine environments, few studies have examined the impact of ice on detection of acoustic transmissions [46]. Our results suggest that during periods of ice formation and ice break-up, there may be additional acoustic noise in the environment that impacts DE (e.g., ice cracking, ice abrasion); whereas thicker ice may be more stable, thus creating high DE similar to when ice is not present in the lake. It is possible that this could be a result of the thick ice reflecting acoustic signals downward through the water column. Alternatively, thick and stable ice may form a barrier between wind-generated noise and the telemetry gear and reducing wind-generated waves.

A variable that is often overlooked in retrospective range analyses is the number of fish detections occurring on the receivers throughout the study period. The duration of a complete acoustic transmission varies by manufacturer but is $\sim 3.5 \mathrm{~s}$ for Vemco tags [28]. During the time that one transmission is being detected and recorded by a receiver, a transmission from another tag could arrive at the receiver and interfere with the receiver's ability to properly decode either signal $[17,18]$. Larger numbers of fish present in an array at the same time increase the probability of these signal code collisions occurring [18]. The number of tagged fishes concurrently present in a system can depend on the animal's behaviour (e.g., schooling, highly resident species, animals with small space use, migratory species, etc.) and thus, it is important to consider these variables in study design when selecting the nominal delay of tags and the sample size. Retrospective analysis of receiver performance in relation to noise levels and sources in our study suggested that noise produced by environmental sources and tagged fish present in the system were not at levels that would have a significant impact on DE [see Additional file 1]. Inclusion of the number of fish detections in the best fitting model was likely a result of increased detection of tagged fish associated with increased DE.

A possible confounding factor in our study stems from calculating DE as a daily metric. We calculated DE at a daily level because the tags used were programmed with random transmission intervals (i.e., 1750-1850 s) to avoid potential conflicts with other tags in the area and it is not possible to predict when the tag was expected to transmit. Due to the nominal delay of the tags, alternative analyses were not possible, such as treating each transmission as a binomial distribution at the 30-min scale. Calculating DE at a daily level allowed for more possible values of DE (i.e., a maximum of 48 transmissions per day results in 49 possible values of DE as a daily metric) than using a shorter time period. For predictor variables that vary throughout the day (e.g., wind is often highly variable), we are likely to miss the effect of extreme values on DE via this averaging. The "instantaneous effect" of these environmental conditions is likely to be more extreme than the averages we present, potentially resulting in periods throughout a day when DE and DR are greatly compromised. As such, the influence of environmental conditions on DE presented in this study may be an underestimate. Additionally, complex non-linear models can be biased resulting in low AIC values [47]. Consequently, our interpretation of model selection results has been cautious; nevertheless, it is evident that environmental variables are contributory.

\section{Conclusions}

Here, we conducted range testing using an extensive telemetry dataset in a system that is underrepresented in acoustic telemetry range studies and contributed to our understanding of acoustic telemetry performance in freshwater. As more researchers incorporate telemetry technologies in their studies, it becomes increasingly important to address associated issues to improve the quality and interpretation of data. The unique performance of acoustic telemetry arrays that has been demonstrated in a variety of environments highlights the value 
of incorporating methods for in situ range testing and retrospective analysis of $\mathrm{DE}$ in study design. While many range studies have been executed to determine DE and DR and how they fluctuate spatially and temporally in a large-scale system or type of environment, it is important to acknowledge the complexity of each unique study location and the non-linear effects of environmental variables. Our study revealed that the effect of individual environmental conditions may increase or decrease with changes in distance or depth and is inconsistent across tag types as illustrated by interactions we presented between different variables. Range studies are valuable in determining DE and DR prior to a telemetry study to inform study design and retrospective analysis of range is important to determine changes in $\mathrm{DE}$ and the potential impacts of the environment throughout a telemetry study. However, unless one environmental variable or interaction has an overwhelming effect on DE and DR at a specific location or during a certain period and the exact location and depth of the study animal are known, it may be difficult to assess range in a manner that can be applied directly to detection data of tagged animals. We recommend conducting range studies concurrent with animal telemetry to estimate variation in DE and DR that most closely matches the environment experienced by study animals. Future range studies in freshwater lakes should compare static and mobile range testing to evaluate how accurately DE of a sentinel tag represents that of a mobile tag to inform on whether static range testing can be used to accurately interpret detections of mobile tagged individuals.

\section{Supplementary information}

Supplementary information accompanies this paper at https://doi. org/10.1186/s40317-019-0179-1.

Additional file 1. Additional material showing receiver performance metrics calculated for receivers in the array during the entire study period (October 2015-May 2016) and additional environmental model results.

\section{Acknowledgements}

We thank the crew of the OMNRF Lake Ontario Explorer and the NYSDEC Seth Green Research Vessel, particularly captain Jon Chicoine and captain Alan Fairbanks, respectively. We thank D. Webber (Vemco) for early design discussions. We also thank the anonymous reviewers for helpful and constructive comments on a previous version of this manuscript.

\section{Authors' contributions}

$\mathrm{EAH}, \mathrm{ATF}$, and TBJ conceived the ideas and designed the methodology; $\mathrm{EAH}$, ATF, and TBJ collected the data; NVK and JKM analyzed the data; NVK led the writing of the manuscript. All authors read and approved the final manuscript.

\section{Funding}

Funding for this research was provided by Great Lakes Fishery Commission Grants to ATF, TBJ and EAH (Project ID_2015_FIS_44040 and 2017 JOH 44065), MITACs Grant to ATF and EAH, and USFWS Grant to ATF, TBJ and EAH. NVK was supported by an NSERC scholarship.

\section{Availability of data and materials}

The datasets used and/or analyzed during the current study are available from the corresponding author upon reasonable request.

Ethics approval and consent to participate

Not applicable.

\section{Consent for publication}

Not applicable.

\section{Competing interests}

The authors declare that they have no competing interests.

\section{Author details}

${ }^{1}$ Great Lakes Institute for Environmental Research, University of Windsor, Windsor, ON, Canada. ${ }^{2}$ Centre for Marine Applied Research, Dartmouth, NS, Canada. ${ }^{3}$ Ontario Ministry of Natural Resources and Forestry, Glenora Fisheries Station, Picton, ON, Canada.

Received: 28 March 2019 Accepted: 31 August 2019

Published online: 14 September 2019

References

1. Hussey NE, Kessel ST, Aarestrup K, Cooke SJ, Cowley PD, Fisk AT, et al. Aquatic animal telemetry: a panoramic window into the underwater world. Science. 2015;348:1255642.

2. Brooks JL, Boston C, Doka S, Gorsky D, Gustavson K, Hondorp D, et al. Use of fish telemetry in rehabilitation planning, management, and monitoring in areas of concern in the Laurentian Great Lakes. Environ Manage. 2017;60:1139-54

3. Crossin GT, Heupel MR, Holbrook CM, Hussey NE, Lowerre-Barbieri SK, Nguyen VM, et al. Acoustic telemetry and fisheries management. Ecol Appl. 2017:27:1031-49.

4. Halfyard EA, Webber D, Del Papa J, Leadley T, Kessel ST, Colborne SF, et al. Evaluation of an acoustic telemetry transmitter designed to identify predation events. Methods Ecol Evol. 2017;8:1063-71.

5. Lu J, Deng ZD, Li H, Myjak MJ, Martinez JJ, Xiao J, et al. A small long-life acoustic transmitter for studying the behaviour of aquatic animals. Rev Sci Instrum. 2016;87:114902.

6. Cooke SJ, Midwood JD, Thiem JD, Klimley P, Lucas MC, Thorstad EB, et al. Tacking animals in freshwater with electronic tags: past, present and future. Anim Biotelemetry. 2013;1:1-19.

7. Donaldson MR, Hinch SG, Suski CD, Fisk AT, Heupel MR, Cooke SJ. Making connections in aquatic ecosystems with acoustic telemetry monitoring. Front Ecol Environ. 2014;12:565-73.

8. Heupel MR, Semmens JM, Hobday AJ. Automated acoustic tracking of aquatic animals: scales, design and deployment of listening station arrays. Mar Freshwater Res. 2006:57:1-13.

9. Melnychuk MC. Detection efficiency in telemetry studies: definitions and evaluation methods. In: Adams NS, Beeman JW, Eiler JH, editors. Telemetry techniques: a user guide for fisheries research. Bethesda: American Fisheries Society; 2012. p. 339-57.

10. Hayden TA, Holbrook CM, Binder TR, Dettmers JM, Cooke SJ, Vandergoot CS, et al. Probability of acoustic transmitter detections by receiver lines in Lake Huron: results of multi-year field tests and simulations. Anim Biotelemetry. 2016;4:1-14.

11. Payne NL, Gillanders BM, Webber DM, Semmens JM. Interpreting diel activity patterns from acoustic telemetry: the need for controls. Mar Ecol Prog Ser. 2010;419:295-301.

12. Lacroix GL, Voegeli FA. Development of automated monitoring systems for ultrasonic transmitters. In: Moore A, Russell I, editors. Fish telemetry: proceedings of the 3rd conference on fish telemetry in Europe. Lowestoft: CEFAS; 2000. p. 37-50.

13. Clements $\mathrm{S}$, Jepsen D, Karnowski M. Optimization of an acoustic telemetry array for detecting transmitter-implanted fish. N Am J Fish Manage. 2005;25:429-36.

14. Simpfendorfer CA, Heupel MR, Collins AB. Variation in the performance of acoustic receivers and its implications for positioning algorithms in a riverine setting. Can J Fish Aquat Sci. 2008;65:482-92. 
15. Voegeli FA, Pincock DG. Overview of underwater acoustics as it applies to telemetry. In: Baras E, Philippart JC, editors. Underwater biotelemetry. Liege: University of Liege; 1996. p. 23-30.

16. Thorstad EB, Økland F, Rowsell S, McKinley RS. A system for automatic recording of fish tagged with coded acoustic transmitters. Fish Manag Ecol. 2000;7:281-94.

17. Voegeli FA, Lacroix GL, Anderson JM. Development of miniature pingers for tracking Atlantic salmon smolts at sea. Hydrobiologia. 1998:371(372):35-46.

18. Pincock DG. False detections: what they are and how to remove them from detection data. Vemco Inc. 2012. http://vemco.com/wp-content/ uploads/2012/11/false_detections.pdf. Accessed 19 Nov 2018.

19. Kessel ST, Cooke SJ, Heupel MR, Hussey NE, Simpfendorfer CA, Vagle $S$, et al. A review of detection range testing in aquatic passive acoustic telemetry studies. Rev Fish Biol Fisher. 2014;24:199-218.

20. Jossart J, Nemeth RS, Primack A, Stolz R. Extreme passive acoustic telemetry detection variability on a mesophotic coral reef, United States Virgin Islands. Mar Biol. 2017;164:180.

21. Huveneers C, Simpfendorfer CA, Kim S, Semmens JM, Hobday AJ, Pederson $\mathrm{H}$, et al. The influence of environmental parameters on the performance and detection range of acoustic receivers. Methods Ecol Evol. 2016;7:825-35.

22. How JR, de Lestang S. Acoustic tracking: issues affecting design, analysis and interpretation of data from movement studies. Mar Freshwater Res. 2012;63:312-24

23. Cagua EF, Berumen ML, Tyler EHM. Topography and biological noise determine acoustic detectability on coral reefs. Coral Reefs. 2013;32:1123-34.

24. Heupel MR, Reiss KL, Yeiser BG, Simpfendorfer CA. Effects of biofouling on performance of moored data logging acoustic receivers. Limnol Oceanogr-Meth. 2008;6:327-35.

25. Gjelland KO, Hedger RD. Environmental influence on transmitter detection probability in biotelemetry: developing a general model of acoustic transmission. Methods Ecol Evol. 2013;4:665-74.

26. Singh L, Downey NJ, Roberts MJ, Webber DM, Smale MJ, van den Berg MA, et al. Design and calibration of an acoustic telemetry system subject to upwelling events. Afr J Mar Sci. 2009;31:355-64.

27. Stocks JR, Gray CA, Taylor MD. Testing the effects of near-shore environmental variables on acoustic detections: implications on telemetry array design and data interpretation. Mar Technol Soc J. 2014;48:28-35.

28. Selby TH, Hart KM, Fujisaki I, Smith BJ, Pollock CJ, Hillis-Starr Z, et al. Can you hear me now? Range-testing a submerged passive acoustic receiver array in a Caribbean coral reef habitat. Ecol Evol. 2016;6:4823-35.

29. Wood SN. Generalized additive models: an introduction with R. Boca Raton: Chapman \& Hall/CRC; 2006.

30. Zuur AF, Saveliev AA, leno EN, Smith GM. Mixed effects models and extension in ecology with R. New York: Springer; 2009.

31. Wood SN. Generalized additive models: an introduction with R. 2nd ed. Boca Raton: Chapman \& Hall/CRC; 2017.

32. Kessel ST, Hussey NE, Webber DM, Gruber SH, Young JM, Smale MJ, et al. Close proximity detection interference with acoustic telemetry: the importance of considering tag power output in low ambient noise environments. Anim Biotelemetry. 2015:3:1-14.
33. Scherrer SR, Rideout BP, Giorli G, Nosal E, Weng KC. Depth- and rangedependent variation in the performance of aquatic telemetry systems: understanding and predicting the susceptibility of acoustic tag-receiver pairs to close proximity detection interference. Peer J. 2018;6:e4249.

34. Sóskuthy M. Generalised additive mixed models for dynamic analysis in linguistics: a practical introduction. 2017. https://arxiv.org/ abs/1703.05339. Accessed 3 Nov 2018.

35. Hyndman R, Khandakar Y. Automatic time series forecasting: the forecast package for R. J Stat Softw. 2008;26:1-22.

36. R Development Core Team. (2018). R: a language and environment for statistical computing. R Foundation for Statistical Computing, Vienna, Austria. https://www.R-project.org/.

37. Hazel J, Hamann M, Lawler IR. Home range of immature green turtles tracked at an offshore tropical reef using automated passive acoustic technology. Mar Biol. 2013;160:617-27.

38. Roy R, Beguin J, Argillier C, Tissot L, Smith F, Smedbol S, et al. Testing the VEMCO Positioning System: spatial distribution of the probability of location and the positioning error in a reservoir. Anim Biotelemetry. 2014;2:1-6.

39. Espinoza M, Farrugia TJ, Webber DM, Smith F, Lowe CG. Testing a new acoustic telemetry technique to quantify long-term, fine-scale movements of aquatic animals. Fish Res. 2011;108:364-71.

40. Baktoft H, Zajicek P, Klefoth T, Svendsen JC, Jacobsen L, Pederson MW, et al. Performance assessment of two whole-lake acoustic positional telemetry systems - is reality mining of free-ranging aquatic animals technologically possible? PLOS ONE. 2015;10:e0126534.

41. Shroyer SM, Logsdon DE. Detection distances of selected radio and acoustic tags in Minnesota lakes and rivers. N Am J Fish Manage. 2009;29:876-84.

42. Cotton CF. Factors affecting reception range of ultrasonic tags in a Georgia estuary. Mar Technol Soc J. 2010;44:17-24.

43. Radford CA, Jeffs AG, Tindle CT, Montgomery JC. Temporal patterns in ambient noise of biological origin from a shallow water temperate reef. Oecologia. 2008;156:921-9.

44. Kaplan MB, Mooney TA, Partan J, Solow AR. Coral reef species assemblages are associated with ambient soundscapes. Mar Ecol Prog Ser. 2015;533:93-107

45. Mathies NH, Ogburn MB, McFall G, Fangman S. Environmental interference factors affecting detection range in acoustic telemetry studies using fixed receiver arrays. Mar Ecol Prog Ser. 2014;195:27-38.

46. Kessel ST, Hussey NE, Crawford RE, Yurkowski DJ, O'Neill CV, Fisk AT. Distinct patterns of Arctic cod (Boreogadus saida) presence and absence in a shallow high Arctic embayment, revealed across open-water and icecovered periods through acoustic telemetry. Polar Biol. 2016;39:1057-68.

47. Wood SN, Natalya P, Säfken B. Smoothing parameter and model selection for general smooth models. J Am Stat Assoc. 2016;111:1548-63.

\section{Publisher's Note}

Springer Nature remains neutral with regard to jurisdictional claims in published maps and institutional affiliations.

Ready to submit your research? Choose BMC and benefit from

- fast, convenient online submission

- thorough peer review by experienced researchers in your field

- rapid publication on acceptance

- support for research data, including large and complex data types

- gold Open Access which fosters wider collaboration and increased citations

- maximum visibility for your research: over $100 \mathrm{M}$ website views per year

At BMC, research is always in progress.

Learn more biomedcentral.com/submissions 